\title{
Effect of In-service Training Program on Minimizing Nursing Intravenous Medication Process Errors by Syringe Through Intravenous Catheter
}

\author{
Ghada Hassan Ahmed, Sahra Zaki Azer*, HananAbd El-Razik AbdEl-all \\ Medical-Surgical Nursing Department, Faculty of Nursing, Assiut University, Assiut, Egypt \\ Email address: \\ sahraazer@yahoo.com (S. Z. Azer) \\ ${ }^{*}$ Corresponding author \\ To cite this article: \\ Ghada Hassan Ahmed, SahraZaki Azer, HananAbd El-Razik AbdEl-all. Effect of In-service Training Program on Minimizing Nursing \\ Intravenous Medication Process Errors by Syringe through Intravenous Catheter. American Journal of Nursing Science. \\ Vol. 8, No. 4, 2019, pp. 153-162. doi: 10.11648/j.ajns.20190804.16
}

Received: May 12, 2019; Accepted: June 15, 2019; Published: June 26, 2019

\begin{abstract}
The dangerous events caused by medication errors are one of the main challenges faced in the hospital. The current study aimed to evaluate the effect of in-service training program on minimizing nursing intravenous medication process errors by syringe through intravenous catheter. Design; Quasi-experimental study was used in this study. Setting: Surgical wards (A, B, and C) at Assuit University Hospital. Subjects: all available nurses were in the age group between 18-60 years, and both male and female. Tools: Nurses knowledge questionnaire sheet, Nurses' practice checklist for intravenous medication process, and in-service training program. Results: the majority of nurses were females, two thirds their age ranged from ( $20>30$ years), and their years of work experience were more than 10 years. The majority of them had not attainting training program related to intravenous medication process. Conclusion: there was statistically significant difference between pre and post implementation of in-service training program as regard total scores of knowledge and practice about nursing intravenous medication process errors. Recommendations: Development of standard guideline medication administration process should be available at all units in the hospitals.
\end{abstract}

Keywords: In-service Training Program, Intravenous Catheter, Intravenous Medication Process Errors

\section{Introduction}

Patient safety is a key aspect in the care of the patients and one of the important parameters to determine the quality of care. Medication errors have been identified as one of the most common type of errors affecting patient safety, ranging from 42 to $59 \%$ of all medical errors [1]. The nursing medication process involves the preparation, administration, and documentation in a continuous process through a series of actions [2,3].

Medication errors, defined as any preventable event that may cause or lead to inappropriate medication use or patient harm while the medication is in the control of the healthcare professional, patient, or consumer. Such events may be related to professional practice, healthcare products, procedures, and systems, including prescribing, order communication, product labeling, packaging, and nomenclature, compounding, dispensing, distribution, administration, education, monitoring, and use [4, 5].

A Worldwide, the prevalence of all types of medication errors is reported to be $2 \%-5 \%$ of all hospital admissions; many of which are deemed preventable [6]. Medication errors are the eighth leading cause of death in the United States (US), and they represent the single largest cause of errors in the hospital setting, accounting for $>7000$ cases deaths annually [7].

Life threatening errors have been associated with intravenous (IV) medications [8]. In the US $60 \%$ of serious and life-threatening medication errors that occur in patients involved IV drugs; in the United Kingdom approximately $56 \%$ of the errors administered with IV drugs. Although only a few medications are administered IV in the hospital setting, the (IV) drugs account for the majority of medication errors. A high incidence of medication errors related to IV therapy was found in Germany, where $23 \%$ of the total medication 
errors occur during IV administration. In Ethiopia, the prevalence of medication administration errors (MAEs) was reported to be $55 \%[9,10]$.

Nurses play an important role in improving health standards. Hence, they need to be updated about theoretical and practical knowledge in this field [11]. In fact, in-service training serves to update the staff's occupational knowledge and professional skills and improve the best practices for fulfilling various tasks and responsibilities. Active participation of nurses in in-service training can lead to effective learning and development in their field of work [12].

Training is an essential factor contributing to greater efficiency of the nursing staff and organizations. An inservice program is a professional training or staff development effort, where professionals are trained and discuss their work with others in their peer group [13]. Training programs are essential for the survival and viability of the organization in the competition arena [14]. In-service training includes a set of measures taken to promote empowerment and competency among employees for the better undertaking of their tasks, thus helping the organization to achieve its goals [15].

\section{Significance of the Study}

Medications errors are among the most common health threatening mistakes that affect patient care. Such mistakes are considered as a global problem which increases mortality rates, length of hospital stay, and related cost. Nurses frequently administer medications to patients and play a key role in preventing medication errors. So; they should have knowledge, and being skillful in preparing, administering and documenting the intravenous medication. Hence, this study was carried out to evaluate the effect of in-service training program on minimizing nursing intravenous medication process errors by syringe through intravenous catheter.

\section{Aim of the Study}

The present study was undertaken in order to evaluate the effect of in-service training program on minimizing nursing intravenous medication process errors by syringe through intravenous catheter.

\section{Research Hypothesis}

To fulfill the aim of this study the following hypothesis was formulated: Nurses that were received in-service training program about nursing intravenous medication process will be show higher scores in knowledge level and practice than pre implementation of in-service training program.

\section{Participants and Methods}

\subsection{Research Design}

A quasi-experimental study was conducted in the form of a pre/post-test with intervention.

Setting of the study:

The study was conducted in surgical wards (A, B, and C) at Assuit University Hospital.

\subsection{Sample}

All available nurses (38) were participated at this study. Nurses for this study met the following criteria: were working in surgical ward regardless of status or shift and their ages ranged from 18 - 60 years.

\subsection{Tools for Data Collection}

Three tools used for data collection in this study, included the following:

Tool 1: Nurses knowledge questionnaire sheet: This tool was developed to assess nurses' knowledge about intravenous medication process by syringe through intravenous catheter, it included two parts;

Part I: Nurses' demographic data:

Used to assess demographic data of the study subjects, such as age, sex, marital status, level of education, surgical unit, work experience years, attainting training program related to intravenous medication process covered post the basic course.

Part II: Nurses' knowledge about intravenous medication process by syringe through intravenous catheter (pre/post): It consists of 20 items covering information about intravenous medication process.

Scoring system:

The total scores were $(100 \%)$, those who obtained less than $(70 \%)$ were considered have unsatisfactory. While those who obtained more than $(70 \%)$ were considered have satisfactory level of knowledge.

Tool 2: Nurses' practice checklist for intravenous medication process by syringe through intravenous catheter (pre/post): This tool was developed by the researcher after review of related literature. It was used to assess the surgical nurses' practice about steps for preparation, administration and documentation of intravenous medication. Which included two parts:

Part I: Medication preparation checklist: it included; aspirating from ampoules (glass or plastic), aspirating from a vial, and dissolving powder medicine.

Part II: Medication administration checklist which included steps of intravenous medication administration by syringe through intravenous catheter.

Scoring system:

The total score of observation checklist sheet was (45 steps) (medication preparation (34 steps) and medication administration (11 steps), each item in checklist was scored as follow: two degrees for each step that done correct (correctly, in time and with the required frequency) and one degree for each step done incorrect (incorrectly, not in time and without the required frequency) and zero for step that not done. The total scores of practice were $(100 \%)$. Those who obtained less than $(70 \%)$ were considered have 
inadequate level of practice. While those who obtained more than $(70 \%)$ were considered have adequate level of practice.

Tool 3: An in-service training program:

This tool developed by the researchers based on the review of the relevant literature to provide knowledge and practice about intravenous medication process. The in-service training program included two parts;

Part (1) Nurses' knowledge about nursing intravenous medication process included general information about intravenous medications, and medication errors.

Part (2) Nurses' practice for intravenous medication process by syringe through intravenous catheter included; aspirating from ampoules (glass or plastic), aspirating from a vial, dissolving powder medicine, and steps of intravenous medication administration by syringe through intravenous catheter.

\subsection{Method}

a Approval to conduct the study; an official letters was issued to the director of surgical wards at Assiut university hospital.

b Protection of the human rights; each nurse were informed about the purpose, and the nature of the study. The nurses were informed that their participation is totally voluntary and the confidentiality and anonymity were assured.

c Period of study: A pilot study was conducted on $10 \%$ of the study sample (4 nurses) in a selected setting to evaluate the applicability and clarity of the tools. According to this pilot study, the required modifications were made. Those nurses who were involved in the pilot study were included in the study.

d Tools Validity and Reliability: The tools were tested for content validity by 5 expertise in the medical and medical surgical nursing field to ascertain relevance and competence \& reliability were tested by using Cronbach's coaefficient alpha.

e Three phases were followed to accomplish the purpose of the study:

Preparatory phase (assessment and planning):

a Structured nursing intravenous medication process and nurses' practice checklist tool pre implementation of inservice training program; it took a period of one month.

b An assessment of nurses' knowledge was carried out for each nurse using (Tool I).

c Thirty eight nurses were observed by the researchers for their performance skills regarding nursing intravenous medication process by syringe through intravenous catheter in the morning and afternoon shifts in surgical wards by the researchers using (tool II).

Implementation phase:

a Data were collected from general surgery wards at Assiut University Hospital during the period from October 2018 to March 2019, with the researchers present in the wards either between $9.00 \mathrm{am}, 11.00 \mathrm{am}$ or $4.00 \mathrm{pm}$ and $6.00 \mathrm{pm}$, as these were the time for the routine intravenous medication preparation and administration in each ward.

b After explaining the study objectives to the nurses who willing to participate in the study completed the nurses' demographic data questionnaire were assessment through face-to-face interviews.

c The face-to-face interview technique was used so as to attract the subjects' trust and cooperation.

d Surgical nurses training were arranged by the researchers along 3 sessions.

e Implementation took place for $30 \mathrm{~min}$, by means of a presentation and video about preparation and administration of intravenous medication by syringe, after ending the morning shift.

$\mathrm{f}$ In addition, questions were answered, and demonstration was utilized by the researcher in training; also the researcher used program, to reinforce the information.

$\mathrm{g}$ Following the presentation, the training program was available to all the nurses in the ward.

An in-service training program session:

The in-service training program was developed by the researchers based on the review of relevant literature and available resources. There were a total three sessions were conducted for each nurses, each session (30) minutes. Each session usually started by a summary of what had been taught during the previous session and the objectives of the new session. After each session there was 10 minutes for discussion and give feedback. Reinforcement of teaching was performed according to nurses needs to ensure their understanding. Each nurse in the study group obtains a copy of the in-service training program booklet. The researchers used pictures for illustrations, and video to educate the nurses.

a The first session: Was started during first interview after taking demographic data, it contains two parts:

Part I: Information about the preparation of intravenous injection through intravenous catheter included; follow the right of medication administration, perform double check to verify the correct correspondence between prescription, wash hands prior to preparation, wear gloves during preparation, inspects medication and diluent for the expiration date, keep syringe and needle sterile, uses disinfectant gauze to break, takes care that dissolves medicines, and waits for the disinfection solution to dry.

Part II: Information about administration of intravenous injection through intravenous catheter; inform the patient about administration of drug, inspects the intravenous catheter for phlebitis, administration the right drug to the right patient, confirm when the last dose was given, stay in the patients room after administering the drug, dispose materials in dedicated containers, and document all relevant information.

b The second session: it included practice about aspirating, dissolving and administration of intravenous injection through intravenous catheter contains four parts: 
Part I: teach the nurse how to perform aspirating from ampoules (Glass or plastic).

Part II: teach the nurse how to perform aspirating from a vial.

Part III: teach the nurse how to perform dissolving powder medicine.

Part V: teach the nurse how to perform administration of intravenous injection through intravenous catheter.

Evaluation phase:

Nurses were evaluated by the researchers using nurses' practice checklist (tool II) and structured intravenous medication process knowledge (tool I part 2).

Statistical analysis

The data were tested for normality using the AndersonDarling test and for homogeneity variances prior to further statistical analysis. Categorical variables were described by number and percent $(\mathrm{N}, \%)$, where continuous variables described by mean and standard deviation (Mean, SD). Chisquare test and fisher exact test used to compare between categorical variables where compare between continuous variables by t-test land ANOVA TEST. A two-tailed $\mathrm{p}<$ 0.05 was considered statistically significant. We are used person Correlation to appear the association between scores. All analyses were performed with the IBM SPSS 20.0 software.

\section{Results}

Table 1: The present study results show that the majority of the nurses were females $(97.4 \%),(71.1 \%)$ married, $(63.2 \%)$ their age ranged from $(20>30$ years $)$, nursing diploma was the highest proportion $(94.7 \%)$, more than one third $(47.4 \%)$ were working in surgical B and years of work experience were more than 10 years. $(86.8 \%)$ of them had not attainting training program related to intravenous medication process covered during the post course.

Table 2: this table mentioned that there was statistically significant difference between pre and post in-service training program as regard level of knowledge about intravenous medication process by syringe through intravenous catheter.

Figure 1: this figure illustrated that there was statistically significant difference between pre and post implementation of in-service training program as regard total score of knowledge about intravenous medication process by syringe through intravenous catheter pre and post in-service training program.

Table 3: summarize that there was the statistically significant difference between pre and post implementation of in-service training program for the studied sample as regards aspirating medication from a vial and dissolving powder medicine in all steps except appropriate size of syringe $\&$ needle and clean up, dispose of waste safely. And select appropriate size of syringe \& needle, verify health care provider's order, invert the vial, keep the tip of the needle in the liquid, with the syringe at eye level determine that the appropriate dose has been reached by volume, slowly withdraw the needle from vial, and wash hands.

Table 4: summarize that there was statistically significant difference between pre and post implementation of in-service training program as regard aspirating medication from ampoule in all steps except clean up, dispose of needle safely. There was no statistically significant difference between pre and post implementation of in-service training programs regard medication administration steps except hand washes and wear gloves, identify the patient, and remove cap from intravenous catheter and disinfect injection point.

Figure 2: There was a statistically significant difference between pre and post implementation of in-service training program for the studied sample as regards total score level of practice (aspirating from ampoules \& a vial, dissolving powder medicine, and medication administration).

Table 5 and Figure 3: This figure reveals that there was a positive correlation between total level of knowledge and practice. That means post implementation of in-service training program increased level of knowledge and practice.

Table 1. Frequency distribution of demographic data for nurses $(n=38)$.

\begin{tabular}{|c|c|c|}
\hline Data & No. & $\%$ \\
\hline \multicolumn{3}{|l|}{ Age group: } \\
\hline $20>30$ years & 24 & 63.2 \\
\hline $30>40$ & 9 & 23.7 \\
\hline $40>49$ & 5 & 13.2 \\
\hline \multicolumn{3}{|l|}{ Sex: } \\
\hline Male & 1 & 2.6 \\
\hline Female & 37 & 97.4 \\
\hline \multicolumn{3}{|l|}{ Marital status: } \\
\hline Single & 11 & 28.9 \\
\hline Married & 27 & 71.1 \\
\hline \multicolumn{3}{|l|}{ Educational level: } \\
\hline Diploma & 36 & 94.7 \\
\hline Techn.institute & 2 & 5.3 \\
\hline Bachelors & 0 & 0.0 \\
\hline \multicolumn{3}{|l|}{ Ward: } \\
\hline Surgical (A) & 6 & 15.8 \\
\hline Surgical (B) & 18 & 47.4 \\
\hline Surgical (C) & 14 & 36.8 \\
\hline \multicolumn{3}{|c|}{ Years of work experience: } \\
\hline Less than 2 year & 11 & 28.9 \\
\hline 2- 5 year & 6 & 15.8 \\
\hline 5- 10 years & 3 & 7.9 \\
\hline more than 10 years & 18 & 47.4 \\
\hline \multicolumn{3}{|c|}{$\begin{array}{l}\text { Attainting training program related to intravenous medication process } \\
\text { covered during the post course: }\end{array}$} \\
\hline Yes & 5 & 13.2 \\
\hline No & 33 & 86.8 \\
\hline
\end{tabular}


Table 2. Frequency distribution of nurses according to level of knowledge about intravenous medication process by syringe through intravenous catheter pre and post in-service training program $(n=38)$.

\begin{tabular}{|c|c|c|c|c|c|c|c|c|c|c|c|c|c|}
\hline \multirow{3}{*}{ level of knowledge } & \multicolumn{6}{|c|}{ Pre } & \multicolumn{6}{|c|}{ Post } & \multirow{3}{*}{ P. value } \\
\hline & \multicolumn{2}{|c|}{ Don't Know } & \multicolumn{2}{|c|}{ Wrong } & \multicolumn{2}{|c|}{ Correct } & \multicolumn{2}{|c|}{ Don't Know } & \multicolumn{2}{|c|}{ Wrong } & \multicolumn{2}{|c|}{ Correct } & \\
\hline & No & $\%$ & No & $\%$ & No & $\%$ & No & $\%$ & No & $\%$ & No & $\%$ & \\
\hline Intravenous medication preparation: & & & & & & & & & & & & & \\
\hline $\begin{array}{l}\text { Follow the } 6 \text { rights of medication } \\
\text { administration. }\end{array}$ & 1 & 2.6 & 26 & 68.4 & 11 & 28.9 & 0 & 0.0 & 0 & 0.0 & 38 & 100.0 & $<0.001 * *$ \\
\hline $\begin{array}{l}\text { Perform a double check to verify the correct } \\
\text { correspondence between prescriptions. }\end{array}$ & 1 & 2.6 & 16 & 42.1 & 21 & 55.3 & 0 & 0.0 & 0 & 0.0 & 38 & 100.0 & $<0.001 * *$ \\
\hline Wash hands prior to preparation. & 0 & 0.0 & 16 & 42.1 & 22 & 57.9 & 0 & 0.0 & 1 & 2.6 & 37 & 97.4 & $<0.001 * *$ \\
\hline Wear gloves during preparation. & 0 & 0.0 & 17 & 44.7 & 21 & 55.3 & 0 & 0.0 & 0 & 0.0 & 38 & 100.0 & $<0.001 * *$ \\
\hline Inspects medication for the expiration date. & 0 & 0.0 & 29 & 76.3 & 9 & 23.7 & 0 & 0.0 & 13 & 34.2 & 25 & 65.8 & $<0.001 * *$ \\
\hline Inspect diluting for the expiration date. & 0 & 0.0 & 22 & 57.9 & 16 & 42.1 & 0 & 0.0 & 12 & 31.6 & 26 & 68.4 & $0.021 *$ \\
\hline Keep syringe, needle sterile. & 0 & 0.0 & 21 & 55.3 & 17 & 44.7 & 0 & 0.0 & 1 & 2.6 & 37 & 97.4 & $<0.001 * *$ \\
\hline $\begin{array}{l}\text { Intravenous antibiotics are stable when } \\
\text { diluted using sodium chloride. }\end{array}$ & 0 & 0.0 & 19 & 50.0 & 19 & 50.0 & 0 & 0.0 & 0 & 0.0 & 38 & 100.0 & $<0.001 * *$ \\
\hline $\begin{array}{l}\text { The intravenous antibiotic vial top should } \\
\text { be swabbed. }\end{array}$ & 0 & 0.0 & 33 & 86.8 & 5 & 13.2 & 0 & 0.0 & 6 & 15.8 & 32 & 84.2 & $<0.001 * *$ \\
\hline Uses disinfectant gauze to break. & 0 & 0.0 & 31 & 81.6 & 7 & 18.4 & 0 & 0.0 & 4 & 10.5 & 34 & 89.5 & $<0.001 * *$ \\
\hline Takes care that dissolves medicines. & 0 & 0.0 & 18 & 47.4 & 20 & 52.6 & 0 & 0.0 & 0 & 0.0 & 38 & 100.0 & $<0.001 * *$ \\
\hline $\begin{array}{l}\text { Waits for the disinfection solution to dry. } \\
\text { Intravenous medication administration: }\end{array}$ & 0 & 0.0 & 37 & 97.4 & 1 & 2.6 & 0 & 0.0 & 7 & 18.4 & 31 & 81.6 & $<0.001 * *$ \\
\hline $\begin{array}{l}\text { Inform the patient about administration of } \\
\text { drug. }\end{array}$ & 0 & 0.0 & 19 & 50.0 & 19 & 50.0 & 0 & 0.0 & 0 & 0.0 & 38 & 100.0 & $<0.001 * *$ \\
\hline $\begin{array}{l}\text { Inspects the intravenous catheter for } \\
\text { phlebitis. }\end{array}$ & 0 & 0.0 & 16 & 42.1 & 22 & 57.9 & 0 & 0.0 & 0 & 0.0 & 38 & 100.0 & $<0.001^{* *}$ \\
\hline $\begin{array}{l}\text { Administration the right drug to the right } \\
\text { patient. }\end{array}$ & 0 & 0.0 & 15 & 39.5 & 23 & 60.5 & 0 & 0.0 & 0 & 0.0 & 38 & 100.0 & $<0.001 * *$ \\
\hline $\begin{array}{l}\text { Administers the medication using the } \\
\text { prescribed. }\end{array}$ & 0 & 0.0 & 16 & 42.1 & 22 & 57.9 & 0 & 0.0 & 0 & 0.0 & 38 & 100.0 & $<0.001 * *$ \\
\hline -Confirm when the last dose was given. & 0 & 0.0 & 19 & 50.0 & 19 & 50.0 & 0 & 0.0 & 1 & 2.6 & 37 & 97.4 & $<0.001 * *$ \\
\hline $\begin{array}{l}\text { Stay in the patients' room after } \\
\text { administering the drug. }\end{array}$ & 0 & 0.0 & 20 & 52.6 & 18 & 47.4 & 0 & 0.0 & 1 & 2.6 & 37 & 97.4 & $<0.001 * *$ \\
\hline $\begin{array}{l}\text { Dispose materials in dedicated containers. } \\
\text { Documentation: }\end{array}$ & 0 & 0.0 & 16 & 42.1 & 22 & 57.9 & 0 & 0.0 & 0 & 0.0 & 38 & 100.0 & $<0.001 * *$ \\
\hline Document all relevant information. & 5 & 13.2 & 33 & 86.8 & 0 & 0.0 & 0 & 0.0 & 37 & 97.4 & 1 & 2.6 & $0.044 *$ \\
\hline
\end{tabular}

- Chi-square test, ${ }^{*}$ Significant difference at $\mathrm{p}$. value $<0.05, * *$ Significant difference at $\mathrm{p}$. value $<0.01$

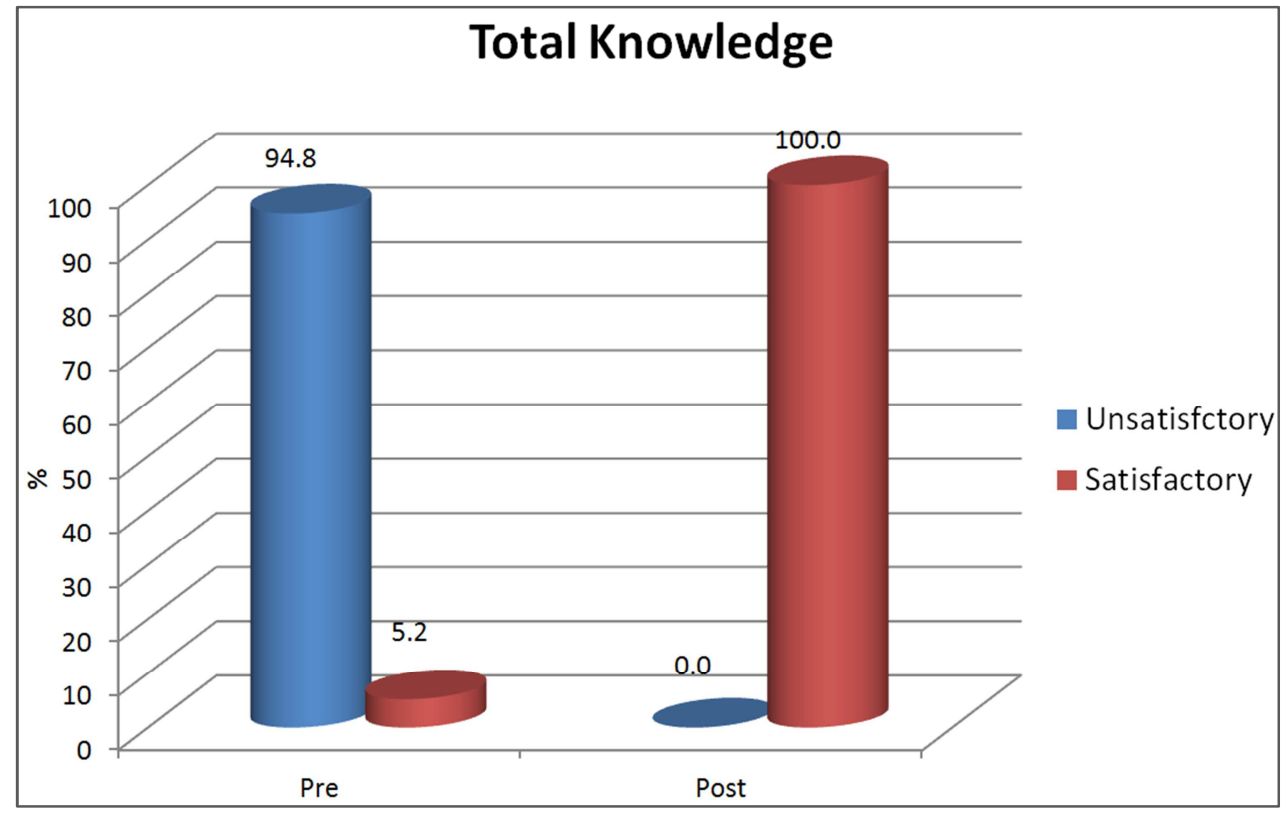

- Chi-square test ** Significant difference at $\mathrm{p}$. value $<0.01$

Figure 1. Total nurses' knowledge score about intravenous medication process by syringe through intravenous catheter pre and post in-service training program $(n=38)$. 
Table 3. Frequency distribution of nurses according to level of practice about aspirating from a vial, and dissolving powder medicine pre and post in-service training program $(n=38)$.

\begin{tabular}{|c|c|c|c|c|c|c|c|c|c|c|c|c|c|}
\hline \multirow{3}{*}{ level of practice } & \multicolumn{6}{|l|}{ Pre } & \multicolumn{6}{|c|}{ Post } & \multirow{3}{*}{ P. value } \\
\hline & \multicolumn{2}{|c|}{ Not done } & \multicolumn{2}{|c|}{ incorrect } & \multicolumn{2}{|c|}{ Correct } & \multicolumn{2}{|c|}{ Not done } & \multicolumn{2}{|c|}{ incorrect } & \multicolumn{2}{|c|}{ Correct } & \\
\hline & No & $\%$ & No & $\%$ & No & $\%$ & No & $\%$ & No & $\%$ & No & $\%$ & \\
\hline \multicolumn{14}{|l|}{ Dissolving powder medicine: } \\
\hline Vial with powder medicine to be dissolved. & 0 & 0.0 & 0 & 0.0 & 38 & 100 & 0 & 0.0 & 0 & 0.0 & 38 & 100 & - \\
\hline Wash hands and wear gloves. & 10 & 26 & 0 & 0.0 & 28 & 74 & 0 & 0 & 0 & 0.0 & 38 & 100 & $0.001 * *$ \\
\hline Disinfect the rubber cap. & 37 & 97 & 0 & 0.0 & 1 & 3 & 7 & 18 & 0 & 0.0 & 31 & 82 & $<0.001 * *$ \\
\hline Aspirate the fluid from the ampoule. & 0 & 0.0 & 0 & 0.0 & 38 & 100 & 0 & 0.0 & 0 & 0.0 & 38 & 100 & - \\
\hline Inject the fluid into the vial. & 0 & 0.0 & 0 & 0.0 & 38 & 100 & 0 & 0.0 & 0 & 0.0 & 38 & 100 & - \\
\hline Shake the medication between hands. & 0 & 0.0 & 36 & 95 & 2 & 5.3 & 0 & 0.0 & 0 & 0.0 & 38 & 100 & 0.152 \\
\hline Insert the needle into the vial. & 0 & 0.0 & 0 & 0.0 & 38 & 100 & 0 & 0.0 & 0 & 0.0 & 38 & 100 & - \\
\hline $\begin{array}{l}\text { Dispose of syringe and ampoule in } \\
\text { appropriate container. }\end{array}$ & 0 & 0.0 & 23 & 60.5 & 15 & 39 & 0 & 0.0 & 0 & 0.0 & 38 & 100 & $<0.001 * *$ \\
\hline $\begin{array}{l}\text { Label the syringe with drug name, dose, } \\
\text { date, and time. }\end{array}$ & 38 & 100 & 0 & 0.0 & 0 & 0 & 12 & 32 & 0 & 0.0 & 26 & 68 & $<0.001^{* *}$ \\
\hline $\begin{array}{l}\text { Wash hands. } \\
\text { Aspirating from a vial: }\end{array}$ & 0 & 0.0 & 0 & 0.0 & 38 & 100 & 0 & 0.0 & 0 & 0.0 & 38 & 100 & - \\
\hline Select appropriate size of syringe $\&$ needle. & 0 & 0.0 & 0 & 0.0 & 38 & 100 & 0 & 0.0 & 0 & 0.0 & 38 & 100 & - \\
\hline Verify health care provider's order. & 0 & 0.0 & 0 & 0.0 & 38 & 100 & 0 & 0.0 & 0 & 0.0 & 38 & 100 & - \\
\hline Wash hands and wear gloves. & 8 & 21 & 29 & 76 & 1 & 2.6 & 0 & 0 & 0 & 0.0 & 38 & 100 & $0.006^{* *}$ \\
\hline Check expiration date. & 38 & 100 & 0 & 0.0 & 0 & 0.0 & 12 & 32 & 0 & 0.0 & 26 & 68 & $<0.001 * *$ \\
\hline $\begin{array}{l}\text { Clean the rubber top of the vial with } 70 \% \\
\text { alcohol pad in a circle motion from center } \\
\text { to outer. }\end{array}$ & 37 & 97 & 1 & 2.6 & 0 & 0 & 7 & 18 & 0 & 0.0 & 31 & 82 & $<0.001 * *$ \\
\hline $\begin{array}{l}\text { Placing the needle in the center of the vial } \\
\text { and inject the air slowly. }\end{array}$ & 0 & 0.0 & 29 & 76 & 9 & 24 & 9 & 24 & 0 & 0.0 & 29 & 76 & $<0.001 * *$ \\
\hline $\begin{array}{l}\text { Invert the vial and slowly using the } \\
\text { negative pressure with draw the medication. }\end{array}$ & 0 & 0.0 & 0 & 0.0 & 38 & 100 & 0 & 0.0 & 0 & 0.0 & 38 & 100 & - \\
\hline Keep the tip of the needle in the liquid. & 0 & 0.0 & 1 & 2.6 & 37 & 97 & 0 & 0.0 & 0 & 0.0 & 38 & 100 & 0.314 \\
\hline $\begin{array}{l}\text { With the syringe at eye level determine } \\
\text { drug volume needed. }\end{array}$ & 0 & 0.0 & 0 & 0.0 & 38 & 100 & 0 & 0.0 & 0 & 0.0 & 38 & 100 & - \\
\hline Slowly withdraw the needle from vial. & 0 & 0.0 & 0 & 0.0 & 38 & 100 & 0 & 0.0 & 0 & 0.0 & 38 & 100 & - \\
\hline Remove possible air from the syringe. & 0 & 0.0 & 23 & 60.5 & 15 & 39 & 0 & 0.0 & 0 & 0.0 & 38 & 100 & $<0.001 * *$ \\
\hline Dispose of vial in appropriate container. & 0 & 0.0 & 23 & 60.5 & 15 & 39 & 0 & 0.0 & 0 & 0.0 & 38 & 100 & $<0.001^{* *}$ \\
\hline $\begin{array}{l}\text { Label the syringe with drug name, dose, } \\
\text { date, and time. }\end{array}$ & 38 & 100 & 0 & 0.0 & 0 & 0.0 & 12 & 32 & 0 & 0.0 & 26 & 68 & $<0.001 * *$ \\
\hline Wash hands. & 0 & 0.0 & 0 & 0.0 & 38 & 100 & 0 & 0.0 & 0 & 0.0 & 38 & 100 & - \\
\hline
\end{tabular}

Chi-square test, * Significant difference at $\mathrm{p}$. value $<0.05,{ }^{*}$ Significant difference at $\mathrm{p}$. value $<0.01$

Table 4. Frequency distribution of nurses according to level of practice about aspirating from ampoules, and medication administration pre and post inservice training program $(n=38)$.

\begin{tabular}{|c|c|c|c|c|c|c|c|c|c|c|c|c|c|}
\hline \multirow{3}{*}{ level of practice } & \multicolumn{6}{|l|}{ Pre } & \multicolumn{6}{|c|}{ Post } & \multirow[t]{3}{*}{ P. value } \\
\hline & \multicolumn{2}{|c|}{ Not done } & \multicolumn{2}{|c|}{ Incorrect } & \multicolumn{2}{|c|}{ Correct } & \multicolumn{2}{|c|}{ Not done } & \multicolumn{2}{|c|}{ incorrect } & \multicolumn{2}{|c|}{ Correct } & \\
\hline & No & $\%$ & No & $\%$ & No & $\%$ & No & $\%$ & No & $\%$ & No & $\%$ & \\
\hline \multicolumn{14}{|l|}{ Aspirating from ampoules (Glass, plastic): } \\
\hline Select appropriate size of syringe \& needle. & 0 & 0.0 & 0 & 0.0 & 38 & 100 & 0 & 0.0 & 0 & 0.0 & 38 & 100 & - \\
\hline Wash hands and wear gloves. & 0 & 0.0 & 38 & 100 & 0 & 0.0 & 0 & 0 & 0 & 0.0 & 38 & 100 & $<0.001 * *$ \\
\hline $\begin{array}{l}\text { Flick the neck of the ampoule repeatedly } \\
\text { with your fingernail, if the medication is } \\
\text { trapped in the top. }\end{array}$ & 5 & 13 & 5 & 13.2 & 28 & 74 & 0 & 0 & 0 & 0.0 & 38 & 100 & $0.003 * *$ \\
\hline $\begin{array}{l}\text { Wrap the sterile gauze pad around the neck, } \\
\text { and snap off the top in an outward directed } \\
\text { away from self. }\end{array}$ & 13 & 34 & 6 & 15.8 & 19 & 50 & 1 & 3 & 0 & 0.0 & 37 & 97 & $<0.001 * *$ \\
\hline $\begin{array}{l}\text { Invert ampoule and place the needle into } \\
\text { the liquid, gently withdraw medication into } \\
\text { the syringe. }\end{array}$ & 0 & 0.0 & 1 & 2.6 & 37 & 97 & 0 & 0.0 & 0 & 0.0 & 38 & 100 & 0.314 \\
\hline Aspirate the fluid from the ampoule. & 0 & 0.0 & 0 & 0.0 & 38 & 100 & 0 & 0.0 & 0 & 0.0 & 38 & 100 & - \\
\hline Remove any air from the syringe. & 0 & 0.0 & 26 & 68.4 & 12 & 32 & 0 & 0.0 & 1 & 2.6 & 37 & 97 & $<0.001 * *$ \\
\hline $\begin{array}{l}\text { Dispose of glass ampoule in appropriate } \\
\text { container. }\end{array}$ & 0 & 0.0 & 2 & 2.6 & 36 & 95 & 0 & 0 & 0 & 0.0 & 38 & 100 & 0.358 \\
\hline $\begin{array}{l}\text { Label the syringe with drug name, dose, } \\
\text { date, and time. }\end{array}$ & 0 & 0.0 & 38 & 100 & 0 & 0.0 & 0 & 0 & 0 & 0.0 & 38 & 100 & $<0.001 * *$ \\
\hline $\begin{array}{l}\text { Wash hands. } \\
\text { Medication administration: }\end{array}$ & 0 & 0.0 & 0 & 0.0 & 38 & 100 & 0 & 0.0 & 0 & 0.0 & 38 & 100 & - \\
\hline
\end{tabular}




\begin{tabular}{|c|c|c|c|c|c|c|c|c|c|c|c|c|c|}
\hline \multirow{3}{*}{ level of practice } & \multicolumn{6}{|l|}{ Pre } & \multicolumn{6}{|c|}{ Post } & \multirow[t]{3}{*}{ P. value } \\
\hline & \multicolumn{2}{|c|}{ Not done } & \multicolumn{2}{|c|}{ Incorrect } & \multicolumn{2}{|c|}{ Correct } & \multicolumn{2}{|c|}{ Not done } & \multicolumn{2}{|c|}{ incorrect } & \multicolumn{2}{|c|}{ Correct } & \\
\hline & No & $\%$ & No & $\%$ & No & $\%$ & No & $\%$ & No & $\%$ & No & $\%$ & \\
\hline $\begin{array}{l}\text { Perform the } 6 \text { rights of medication } \\
\text { administration. }\end{array}$ & 0 & 0.0 & 38 & 100 & 0 & 0.0 & 0 & 0.0 & 0 & 0.0 & 38 & 100 & - \\
\hline Hand washes and wear gloves. & 0 & 0.0 & 35 & 92.1 & 3 & 7.9 & 0 & 0.0 & 9 & 23.7 & 29 & 76.3 & 0.0001 \\
\hline Assess intravenous catheter for patency. & 3 & 7.9 & 0 & 0.0 & 35 & 92.1 & 0 & 0.0 & 0 & 0.0 & 38 & 100 & 0.077 \\
\hline Identify the patient. & 3 & 7.9 & 34 & 89.5 & 1 & 2.6 & 0 & 0.0 & 14 & 36.8 & 24 & 63.2 & 0.0001 \\
\hline Remove needle from the syringe. & 0 & 0.0 & 0 & 0.0 & 38 & 100 & 0 & 0.0 & 0 & 0.0 & 38 & 100 & - \\
\hline $\begin{array}{l}\text { Remove cap from intravenous catheter and } \\
\text { disinfect injection point. }\end{array}$ & 0 & 0.0 & 36 & 94.7 & 2 & 5.3 & 0 & 0.0 & 20 & 52.6 & 18 & 47.4 & 0.0001 \\
\hline $\begin{array}{l}\text { Insert hub into injection point and secure it } \\
\text { carefully. }\end{array}$ & 0 & 0.0 & 0 & 0.0 & 38 & 100 & 0 & 0.0 & 0 & 0.0 & 38 & 100 & - \\
\hline $\begin{array}{l}\text { Administers the medication using the } \\
\text { prescribed. }\end{array}$ & 0 & 0.0 & 0 & 0.0 & 38 & 100 & 0 & 0.0 & 0 & 0.0 & 38 & 100 & - \\
\hline Dispose materials in dedicated containers. & 0 & 0.0 & 0 & 0.0 & 38 & 100 & 0 & 0.0 & 0 & 0.0 & 38 & 100 & - \\
\hline Remove gloves and wash hands. & 0 & 0.0 & 0 & 0.0 & 38 & 100 & 0 & 0.0 & 0 & 0.0 & 38 & 100 & - \\
\hline Document all relevant information. & 0 & 0.0 & 38 & 100 & 0 & 0.0 & 37 & $\begin{array}{l}97 . \\
4\end{array}$ & 0 & 0.0 & 1 & 2.6 & 0.314 \\
\hline
\end{tabular}

- Chi-square test, * Significant difference at p. value $<0.05, * *$ Significant difference at $\mathrm{p}$. value $<0.0$

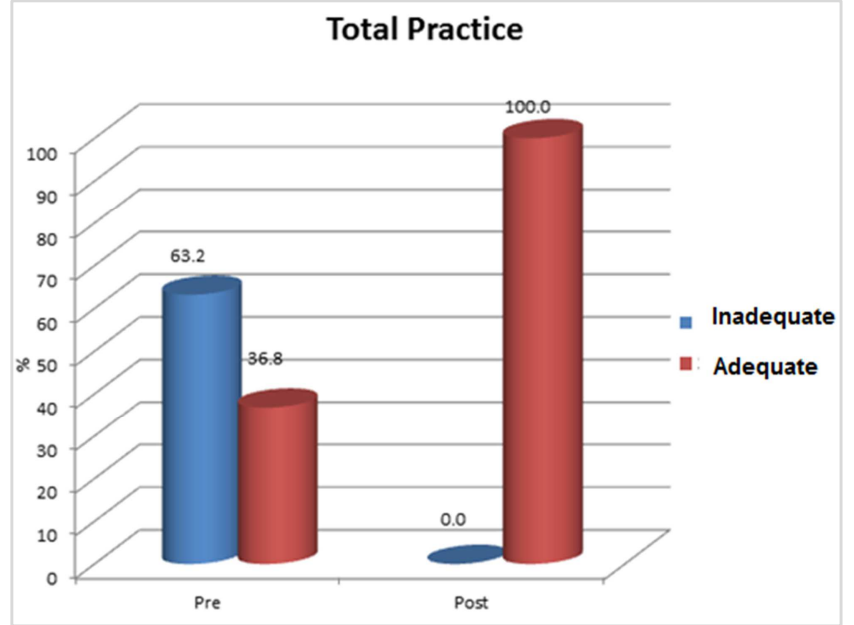

Figure 2. Nurses' total score level of practice (aspirating from ampoules \& a vial, dissolving powder medicine, and medication administration) by syringe through intravenous catheter pre and post in-service training program $(n=$ 38).

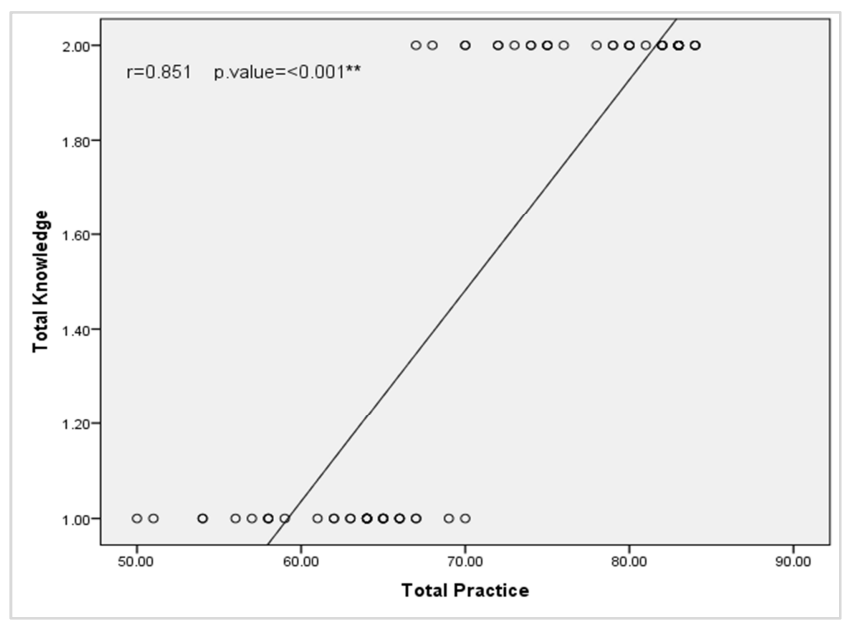

Figure 3. Correlation between total level of knowledge and practice.
Table 5. Correlation coefficient between total nurses' level of knowledge and practice pre and post in-service training program $(n=38)$.

\begin{tabular}{lllllll}
\hline \multirow{2}{*}{ Correlation } & \multicolumn{2}{l}{ Knowledge } & & & & \\
\cline { 2 - 7 } & Pre & & Post & & Total & \\
\hline \multirow{2}{*}{ Practice } & $\mathrm{R}$ & $\mathrm{P}$ & $\mathrm{R}$ & $\mathrm{P}$ & $\mathrm{R}$ & $\mathrm{P}$ \\
& 0.162 & 0.332 & 0.100 & 0.551 & 0.851 & $<0.001 * *$ \\
\hline
\end{tabular}

Statistically Significant Correlation at P. value $<0.01 *$

\section{Discussion}

The result of this study shows that since medication errors in medication process seem to occur mostly because of a lack of knowledge or precision in intravenous medication process, they could be easily corrected by in-service training the nursing staff.

\subsection{Demographic Date for Nurses}

The present study results show that the majority of nurses were female; their age ranged from (20-30years), and nursing diploma was the highest proportion. As regard years of work experience; it was found that more than one third of them was more than 10 years. Regarding the previous attending inservice training; it was found that the majority of study subjects have no in- service training courses related to intravenous medication process.

This finding was supported by [8] who found in their study that most of gender profiles of respondents were females and their age ranged from 22-37 years. The majority of the respondents were diploma holders and less than half of respondents have less than 2 years nursing experience while less than one fifth of them have 10 years or more working experience. Also this finding is in disagreement, with the paper of [16] which mentioned that, more than one third were female; about half was the age of the equal or less than 25 years; majority of them held bachelor degree in nursing and were staff nurses; more than two thirds had nursing experience equals or less than 5 years. 


\subsection{Nurses' Knowledge about Intravenous Medication Process}

The observed significant improvement in studied nurses' knowledge regarding inspect medication for the expiration date, swab the top of IV antibiotic vial, use disinfectant gauze to break neck, wait for the disinfection solution to dry, and document all relevant information when exposed to an training program indicates that these nurses could readily benefit from it. This might be due to the fact that information was simple, in addition to the use of suitable media for clarification, and the guidance offered during application of the program that enhanced the process of learning.

Thus, the improvement points is related to the effectiveness of the training program, which was successful in nurses' acquisition of knowledge. These present study findings are in agreement with [17] who claimed that any training program activities are intended to assist the nurses in acquiring, maintaining, and increasing competence in fulfilling their assigned responsibilities specific to the expectations and objectives of the employer.

In this respect, [18] who stressed that in-service educational and training programs have significant favorable impact in improving nurses' knowledge. They also recommended that educational programs should be continuously organized according to the needs of nurses with subsequent continuing evaluation to the progress and outcome of these programs.

The study also revealed before the training program, nurses had unsatisfactory knowledge about intravenous medication process. This was indicated by their low scores. The researcher believes that, unsatisfaction in knowledge that noticed among nurses' might be attributed to that, after graduation; nurses abandon reading and neglect updating their professional knowledge. Thus, an important reason for the unsatisfactory knowledge of nurses lies in the deteriorating status of their knowledge after they graduate, since nurses refrain from trying to improve their knowledge. Another possible reason might be the absence of any resources or programs for continued nursing education that are essential to upgrade and improve nurses' knowledge during their care for patients.

This present study finding pertaining to unsatisfactory knowledge among nurses is in congruent with $[19,20]$ who emphasized that continuing education programs in nursing care is urgently and consistently needed in order to provide upto-date knowledge and also improve nurses' skills. Therefore, the authors have added, continuing education of the nursing staff can help reduce medication errors. Also [21] highlighted that, nurses and nurse managers need to be educated on medication errors and clearly defined working expectations.

\subsection{Nurses' Practice Regarding Intravenous Medication Process by Syringe Through Intravenous Catheter}

According to the present study findings, nurses practices regarding intravenous medication process by syringe through intravenous catheter were inadequate regarding wash hands and wear gloves, inspect medication for the expiration date, wrap the sterile gauze pad around the neck, and clean the rubber top of the vial with $70 \%$ alcohol pad in a circle motion from center to outer, remove any air from the syringe, label the syringe with drug name, dose, date, and time, dispose of vial in appropriate container, identify the patient, and disinfect injection point in the pre-training.

As or nurses' practice at the post-training, the results have revealed statistically significant improvements in most of the procedural steps. Thus, immediately after implementation of the training program, their performed procedures were observed to have improved sharply, and with a statistically significant difference. This pattern of improvement was consistent in almost all steps of preparation and administration i.e., aspirating from ampoules \& a vial, and dissolving powder medicine. All these procedural steps were significantly improved $(\mathrm{P}<0.001)$ immediately after the application of the training program. Conversely, no statistically significant association could be shown in almost steps of medication administration. This may be due to that all nurses done this skill routinely.

This goes in line with $[22,23]$ which stated that teaching programs for nursing staff constitutes an important part. These programs are urgently designed to assist staff nurses in developing and enhancing their skills needed to provide high standards of care to their patients.

In this respect, [24, 25] documented that the in-service training program has a beneficial effect in improving the nurses' knowledge and skills. They also recommended that educational programs should be organized according to the needs of nurses with continuous evaluation. As well as, [26] who recommended that educational programs should be organized according to the needs of nurses with continuous evaluation and adopting proper checklists for work monitoring to enhance patient and staff awareness; led to reduced process errors, mitigating overall risks, eventually resulting in effective patient care.

On studying the relation between nurses' knowledge and practice. The results in the current study showed a positive correlation between total level of knowledge and practice observed during the post implementation of in-service training program. This finding indicated that skills can be easily improved, especially if linked with their relevant scientific base of knowledge. These results are on the same line with [19] who stated that health care providers are required to have adequate knowledge and skill to safe intravenous medication use.

\section{Conclusion}

There was the statistically significant difference between pre and post implementation of in-service training program for the studied sample as regards aspirating medication from a vial and dissolving powder medicine in all steps except appropriate size of syringe \& needle and clean up, dispose of waste safely. There was statistically significant difference between pre and post implementation of in-service training 
program as regard total scores of knowledge and practice about intravenous medication process by syringe through intravenous catheter. There was a positive correlation between total level of knowledge and practice

\section{Recommendations}

Based on the conclusion of this study, the researcher recommended the following:

1. Development of standard guideline medication administration process (log book) and should be available at all units in the hospitals.

2. Periodic monitoring and supervision of staff nurse in the hospital to assess their level of performance and to ensure plans of action were taken and implemented.

3. Providing sufficient clinical pharmacists experts for responding to any questions or explanation regarding medication administration process for each hospital words.

\section{References}

[1] Fadahunsi, K. P., Akinlua, J. T,. O'Connor, S., Petra A. Gallagher, J, Carroll, C. Majeed, A, O'Donoghue, J. (2018): "Protocol for a systematic review and qualitative synthesis of information quality frameworks in Health". Vol. 9 no (3): p. p10. 16 .

[2] Jonathon R. B.; Savage, Grant T.; Wakefield, Douglas S.; Wakefield, Bonnie J. (2010): Rework and workarounds in nurse medication administration process: Implications for work processes and patient safety, Health Care Management Review: April-June Vol. 35 - Issue 2 - P. P 124-133

[3] Mehammed A., G. and Berhanu B., B, (2017): Work Interruption Experienced by Nurses during Medication Administration Process and Associated Factors, Nursing Research and Practice. Page 7

[4] Agyemang R., \& While A. (2010): Medication errors: Types, causes and impact on nursing practice. British Journal of Nursing (BJN), Vol. 19 (6). P.p 380-385.

[5] Negash G., Kebede Y., \& Hawaze S. (2013): Medication errors in the adult emergency unit of a tertiary care teaching hospital in Addis Ababa. Arch PharmaPrac. Vol. 4 (4): P.p 810.

[6] Brady AM1, Malone AM, Fleming S. (2009): A literature review of the individual and systems factors that contribute to medication errors in nursing practice, National institute of health, Vol. 17 no. (6): P.P 679-97.

[7] Ong W. M., Subasyini S. (2013): Medication errors in intravenous drug preparation and administration. Med J Malaysia. Vol. 68 (1): P.p 52-56.

[8] Shamsuddin A. F., \& Shafie S. D. (2012): Knowledge of nurses in the preparation and administration of intravenous medications, Quality Use of Medicines Research Group, Faculty of Pharmacy, University Kebangsaan Malaysia. Procedia - Social and Behavioral Sciences 60: P.p 602-609.

[9] Eckel S. F., Anderson P., \&Zimmerman C. (2006): User satisfaction with an intravenous medication safety system. Am
J Health Syst Pharm; Vol. 63 (15): P.p1419-1423.

[10] Llewellyn R. L., Gordon P. C., \&Reed A. R. (2011): Drug administration errors-time for national action. S Afr Med J. 101 (5): P.p 93-98.

[11] Ajani K., \& Moez S. (2011): Gap between knowledge and practice in nursing. Procedia Social and Behavioral Sciences; 15. P.p 3927-3931.

[12] Mahmud C., Mohsen S., Abbas E., \& Ahmad A. (2017): Empowering Education: A New Model for In-service Training of Nursing Staff. J Adv Med Educ Prof. Jan; Vol. 5 (1): P.p $26-32$.

[13] Khan R. A. G., Khan F. A., \& Khan M. A. (2011): Impact of training and development on organizational performance. Global Journal of Management and Business Research. Vol. 11 (7): P.p 63-8.

[14] Lee Y. J., Chao C. H., \& Chen C. Y. (2011): The influences of interest in learning and learning hours on learning outcomes of vocational college students in Taiwan: using a teacher's instructional attitude as the moderator. Global Journal of Engineering Education; Vol. 13 (3): P.p 140-153.

[15] Fateminejhad M., \& Kolahjoei A. A. (2013): Effect of shortterm in-service training on organizational performance from the viewpoints of experts of companies affiliated with Jihad agriculture of khuzestan province, Iran. International Journal of Economy, Management and Social Sciences; 2 (12): P.p $1008-1012$.

[16] Fulbrook P., \&Albarran J. (2012): Nurses' medication work: What do nurses know? Journal of Clinical Nursing 19: P.p 3218-3226.

[17] Abd Al-Magid A. S. Mohammed S., A, Alaa Aldeen, Shehata S., Mohammeda Abd Elatef Z., M., (2011): Nursing care standards for cancer patients undergoing chemotherapy. Vol. 8 no (5): P.P108-120 .

[18] Masoud E. S. (2006): The impact of educational and training program on the knowledge and performance of nursing practice in the Hematology and Emergency Units at Pediatric Department of Assiut University Hospital. PhD thesis, Pediatric Nursing. Assiut University Hospital.

[19] Anderson P., \& Townsend T. (2010): Medication errors: Don't let them happen to you. American Nurse Today Vol. 5 (3): P.p 23-28.

[20] Bakr M., Attaha H. (2012): Evaluation of drug administration errors in a teaching hospital. BMC Health Services Research, Vol. 12 (60). doi: 10.1186/1472-6963-P.p12-60.

[21] Elliot J. A., Jacobi J., \&Buss W. (2010): Using innovative technologies to set new safety standards for the infusion of intravenous medications. Hosp Pharm; 37: P.p 1179-1189.

[22] Kimberley S, R, Sandra G., William M. (2010): The Relationship Between Simulation in Nursing Education and Medication Safety, Journal of Nursing Education. Vol. 49, No. (1): P.P 52-55.

[23] Khalil S. S., Mohammad Z. A., EzEldeen M. E., \& Ahmed N. M. (2013): Impact of Implementing A Designed Nursing Intervention Protocol on Nurses' Knowledge and Practice Regarding Patients Undergoing Blood Transfusion D.N.Sc. Med. J. Cairo Univ., Vol. 81, No. 2, June: P.p 163-171. 
[24] Bertsche, TA Bertsche, A. Krieg E-M, Kunz N, Bergmannm K, Hanke G, T Hoppe-Tichy, F Ebinger F, Haefeli WE (2010): Prospective pilot intervention study to prevent medication errors in drugs administered; BMJ quality and safety April, Vol. 19 (5) p. 26.

[25] Vijayakumar A., Sharon E. V., Teena J., Nobil S., \&Nazeer I (2014): A clinical study on drug-related problems associated with intravenous drug administration. J Basic Clin Pharm. Vol. 5 (2): P.p 49-51.

[26] Ookalkar, Anil G. Joshi, Dhananjay S. Ookalkar, (2009): "Quality improvement in haemodialysis process ", International Journal of Quality \& Reliability Management, Vol. 26 Iss: 8, pp. 817-830. 